\title{
Editorial
}

\section{Write less, write well}

\author{
Roberto Cubelli ${ }^{a, *}$ and Sergio Della Sala ${ }^{b}$ \\ ${ }^{a}$ Department of Psychology and Cognitive Sciences, University of Trento, Italy \\ ${ }^{\mathrm{b}}$ Human Cognitive Neuroscience, Psychology, University of Edinburgh, UK
}

I never desire to converse with a man who has written more than he has read.

Samuel Johnson, 1787, p.201

...what I have read is far more important than what I have written.

\section{Jorge Luis Borges, 2000, p.98}

Cortex receives over a thousand submissions per year, of which only ten per cent can be accepted. The vast majority of those turned away will end up published in a different outlet. Similarly, Cortex receives and sometimes publishes manuscripts rejected by other journals. Almost every manuscript is published eventually, whether it is worth it or not. This tendency is receiving a further, cynical boost from predatory Open Access outlets, offering acritical vanity-press covenants of you-pay/we-publish (Bohannon, 2013). Everything gets published, because almost anything can: for incontrovertible proof, see the brilliant "Get me off your fucking mailing list", a hoax paper accepted for publication, containing only the title phrase repeated hundreds of times. We are overwhelmed by below-par studies that add little or nothing to our science, yet we keep submitting and publishing as if there is no tomorrow.

This deluge of publications creates an academic environment in which it is increasingly difficult and time-consuming to distinguish the signal from the noise. Yet established etiquette compels us to consider even modest manuscripts reporting contradictory findings from pedestrian methodology. Overloaded by so much mediocre information, researchers may give up reading altogether, let alone reading deeply, believing they will never master the published data even in one specific topic. They would feel therefore justified to read only the abstracts and cite papers on this basis, resulting in inaccuracies and errors. In the limit, we will ultimately each read only what we write.

As a community, our 'enemies within' are not only questionable scientific practices and fraud (Chambers, 2013); we should also oppose salami publication, self-plagiarism (Della Sala, Grafman, \& Cubelli, 2013), and systems that encourage unrealistic hyper-production, whereby researchers brag dozens of papers per year, as well as the accumulating scum of low-quality pay-to-publish.

In most countries, exercises evaluating research output of institutions require individual scientists and clinicians to select a small number of papers, which they consider their best work, within a pre-defined window of several years. Why does this selectivity not offset the imperative to publish (in quantity) or perish? Part of the reason may be that when individuals, rather than institutions, are evaluated - for appointments, habilitations, promotions, or simply in considering workload - quantity remains highly influential. Perhaps we could partly counter this perilous habit by applying the rules used to scrutinize institutional outputs to individuals as well: individuals presenting their outputs should be asked to list only their best, ignoring the rest. Also the indices commonly used as proxies for academic value remunerate quantity. These are useful as for instance they contrast conflicts of interest, but should be integrated by qualitative informed analyses; we cannot be regulated by numbers alone: see for discussion and proposal the Leiden Manifesto (Hicks, Wouters, Waltman, de Rijcke, \& Rafols, 2015). Individuals, like institutions, should be judged solely by their best.

If we could quell the mania for publication long enough to focus researchers' minds on quality, then reading and studying might be prioritised over the rush to publish even the most mediocre study we carry out. Of course, we do not

\footnotetext{
* Corresponding author.

E-mail address: roberto.cubelli@unitn.it (R. Cubelli). http://dx.doi.org/10.1016/j.cortex.2015.05.008

0010-9452/@ 2015 Elsevier Ltd. All rights reserved.
} 
propose to curtail any individual author's freedom to publish as much as they want. Such a proscriptive solution might, for instance, have the unwelcome consequence of further reducing attempts to replicate previous findings or to publish null results. However, this need not follow, provided that such studies, adequately powered, are recognised as valuable to science (see Cortex's Registered Report format, for a relevant innovation in this direction; Chambers, 2013). We may even envisage a system whereby established researchers would commonly encourage junior researchers to undertake such studies as part of their scientific training. Cultural changes of the sort suggested here may be hard to establish, but the current path does not seem a sustainable way forward.

Similarly, it may be hard to reduce the number of acritical pay-to-publish journals which are mushrooming, capitalising on our vanity or naiveté as well as our professional need to publish. But we could work as a community to make the criteria for indexing journals more stringent. In particular, we may agree that a given outlet gains the stamp of approval only when thorough peer review and transparency of process, together with a clear international audience (authors, reviewers, editors and readers), are in place. We should be allowed to ignore data published in outlets which do not fulfil these criteria.
Reining in our current urge to publish might bring about a more balanced attitude towards academic life, exhorting us to pay heed to the cultural world outside our own lab. If we do so by applying the same rigour that we apply in our research to issues like ethics, dissemination, institutional policy, public engagement and teaching, our science as a whole will benefit. And perhaps we will contribute blunting the weapons of the predatory Open Access market.

\section{R E F E R E N C E S}

Bohannon, J. (2013). Who's afraid of peer review? Science, 342, 60-65.

Borges, J. L. (2000). This craft of verse. In C.-A. Mihăilescu (Ed.). Cambridge (MA): Harvard University Press.

Chambers, C. D. (2013). Registered reports: a new publishing initiative at Cortex. Cortex, 49, 609-610.

Della Sala, S., Grafman, J., \& Cubelli, R. (2013). I copy, therefore I publish. Cortex, 49, 2281-2282.

Hicks, D., Wouters, P., Waltman, L., de Rijcke, S., \& Rafols, I. (2015). The Leiden Manifesto for research metrics. Nature, 520, 429-431.

Johnson, S. (1787). The work of Samuel Johnson in eleven volumes, Vol. XI "Apophthegms, Sentiments, Opinions and Occasional Reflections". London. 